\title{
Genome-wide association study reveals the genetic basis of yield- and quality-related traits in wheat
}

\author{
Le Gao ${ }^{\dagger}$, Chengsheng Meng ${ }^{\dagger}$, Tengfei Yi, Ke Xu, Huiwen Cao, Shuhua Zhang, Xueju Yang ${ }^{*}$ (D) and Yong Zhao*
}

\begin{abstract}
Background: Identifying the loci and dissecting the genetic architecture underlying wheat yield- and qualityrelated traits are essential for wheat breeding. A genome-wide association study was conducted using a highdensity $90 \mathrm{~K} \mathrm{SNP}$ array to analyze the yield- and quality-related traits of 543 bread wheat varieties.

Results: A total of 11,140 polymorphic SNPs were distributed on 21 chromosomes, including 270 significant SNPs associated with 25 yield- and quality-related traits. Additionally, 638 putative candidate genes were detected near the significant SNPs based on BLUP data, including three (TraesCS7A01G482000, TraesCS4B01G343700, and TraesCS6B01G295400) related to spikelet number per spike, diameter of the first internode, and grain volume. The three candidate genes were further analyzed using stage- and tissue- specific gene expression data derived from an RNA-seq analysis. These genes are promising candidates for enhancing yield- and quality-related traits in wheat.

Conclusions: The results of this study provide a new insight to understand the genetic basis of wheat yield and quality. Furthermore, the markers detected in this study may be applicable for marker-assisted selection in wheat breeding programs.
\end{abstract}

Keywords: GWAS, Quality, Single nucleotide polymorphism, Wheat, Yield

\section{Background}

Bread wheat (Triticum aestivum L.), which is a widely cultivated cereal crop that is highly adaptable, provides approximately $21 \%$ of the total calories and $23 \%$ of protein in the human diet (www.fao.org/faostat/en). As a staple food for about $35-40 \%$ of the global population, wheat is a good source of nutrients and has unique gluten properties, making it useful for producing diverse food products [1]. The increasing global population and improvements in the standard of living for many people worldwide have forced breeders to continually aim to produce new high-quality and high-yielding wheat varieties [2].

\footnotetext{
*Correspondence: shmyxj@126.com; zhaoyong_0423@163.com ${ }^{\dagger}$ Le Gao and Chengsheng Meng contributed equally to this work. State Key Laboratory of North China Crop Improvement and Regulation, Hebei Agricultural University, Baoding 071000, Hebei, China
}

Yield and quality are complex traits. Additionally, the limited genetic diversity of bread wheat has resulted in breeding bottlenecks, and the application of traditional breeding methods has led to gradual increases in wheat yield and quality [3]. Genome sequencing and highthroughput chip-based genotyping platforms are critical for clarifying the mechanisms regulating the wheat yield potential and quality as well as for enhancing breeding methods [4]. Several SNP arrays (e.g., $9 \mathrm{~K}, 35 \mathrm{~K}, 90 \mathrm{~K}$, $660 \mathrm{~K}$, and $820 \mathrm{~K})$ have recently been developed. They have been used to analyze bi-parental populations and identify loci (QTLs) controlling yield- and qualityrelated traits [5-9]. However, traditional QTL mapping methods are usually based on specific characteristics of parental populations, and are time-consuming and laborious [10].

(c) The Author(s). 2021 Open Access This article is licensed under a Creative Commons Attribution 4.0 International License, which permits use, sharing, adaptation, distribution and reproduction in any medium or format, as long as you give appropriate credit to the original author(s) and the source, provide a link to the Creative Commons licence, and indicate if changes were made. The images or other third party material in this article are included in the article's Creative Commons licence, unless indicated otherwise in a credit line to the material. If material is not included in the article's Creative Commons licence and your intended use is not permitted by statutory regulation or exceeds the permitted use, you will need to obtain permission directly from the copyright holder. To view a copy of this licence, visit http://creativecommons.org/licenses/by/4.0/. The Creative Commons Public Domain Dedication waiver (http://creativecommons.org/publicdomain/zero/1.0/) applies to the data made available in this article, unless otherwise stated in a credit line to the data. 
GWAS are common in breeding programs because they are more efficient and require less effort in analyzing complex traits under various environmental conditions than other research methods [11]. Specifically, GWASs have been useful for detecting yield-associated loci in wheat, including plant height $(\mathrm{PH})$, kernel number per spike (KNPS) and thousand grain weight (TGW) $[12,13]$. However, because of the need for many seeds and the substantial time required to assess some quality traits, there have been relatively few GWASs regarding wheat quality traits such as wet gluten content (WGC) and grain protein content (GPC) [14, 15]. Moreover, there are few reports describing a GWAS conducted to investigate lodging resistance, which is an important factor influencing wheat yield and quality.

For a GWAS, the size and diversity of the panel are important because a small panel and large linkage disequilibrium (LD) blocks may lead to the identification of false positive associations [16]. Regarding wheat, only a few GWAS for yield and quality traits have involved large natural populations and SNP chips. Furthermore, wheat has been cultivated in China for more than 4000 years and has now been cultivated in 10 major agroecological zones [17]. Due to the long evolutionary period, Chinese wheat germplasms have been artificially selected in different regions and have regional genetic characteristics $[18,19]$. Accordingly, the objectives and requirements for improving wheat varieties differ considerably among these regions. Thus, we performed a GWAS of wheat yield and quality involving 543 representative bread wheat cultivars, including 531 Chinese wheat cultivars from 10 provinces, and a wheat $90 \mathrm{~K}$ SNP array following phenotypic analyses in six environments.

The aim of this study was to identify the stable loci and candidate genes significantly associated with wheat yield and quality. The results described herein may be useful for revealing the genetic basis of yield and quality. The corresponding SNP markers that were identified may ultimately facilitate the breeding of new highquality and high-yielding wheat varieties.

\section{Results}

\section{Phenotypic variation and correlation analysis}

The phenotypic data for the 543 wheat lines characterized regarding growth- and development-related traits, yield-related traits, and quality-related traits in six environments are listed in Table S1. The phenotypic variations among genotypes were determined based on the heritability, range, mean, standard deviation, and the coefficient of variation. There were obvious variations for all traits, especially the coefficient of variation for thrust (TH) $(49.28 \%)$ in the E5 environment. Table S2 provides the estimated correlation coefficients for this combined analysis. The broad-sense heritability $\left(\mathrm{h}^{2}\right)$ for most traits was approximately 0.80 , with the highest and lowest heritabilities detected for PH (0.92) and PET (0.70). Accordingly, most traits were stable and largely determined by genetic factors. The correlation coefficient was highest (0.970) between wet gluten content (WGC) and grain protein content (GPC), but was also relatively high between TGW and GPR (0.919), wet gluten content (WGC) and flour content (FC) (0.842).

\section{Genome-wide association study}

The $90 \mathrm{~K}$ wheat iSelect SNP array with 81,587 SNPs was used for genotyping. After a quality control step, 11,140 SNP markers remained for the association mapping [20]. A total of 270 significant SNP loci associated with yield and quality traits were identified (Table S3, Fig. S1). These SNPs were located on 21 chromosomes and accounted for $1.27-8.47 \%$ of the phenotypic variation. Moreover, 94, 139, and 37 SNPs were in the A, B, and D subgenomes, respectively (Table S3). Of these SNPs, 42 pleiotropic loci associated with two or more traits were detected on chromosomes 1B, 2A, 2B, 2D, 3A, 3B, 3D, $4 \mathrm{~B}, 4 \mathrm{D}, 5 \mathrm{~B}, 5 \mathrm{D}, 6 \mathrm{~B}, 6 \mathrm{D}, 7 \mathrm{~A}$, and $7 \mathrm{~B}$ based on the common loci (Table 1).

\section{Growth and development-related traits}

A total of 28 significant SNP loci for the flag leaf length (FLL) were detected on chromosomes $1 \mathrm{~B}, 1 \mathrm{D}, 2 \mathrm{~A}, 2 \mathrm{~B}$, $2 \mathrm{D}, 3 \mathrm{~A}, 3 \mathrm{~B}, 4 \mathrm{~B}, 5 \mathrm{~A}, 5 \mathrm{~B}, 5 \mathrm{D}, 6 \mathrm{~B}, 6 \mathrm{D}, 7 \mathrm{~A}$, and $7 \mathrm{~B}, \mathrm{ac}-$ counting for $2.44-4.12 \%$ of the phenotypic variation. $\mathrm{Re}-$ garding the flag leaf width (FLW), 33 significant SNP loci were detected on 13 chromosomes $(1 \mathrm{~B}, 2 \mathrm{~B}, 2 \mathrm{D}, 3 \mathrm{~A}$, $3 \mathrm{~B}, 4 \mathrm{~A}, 4 \mathrm{~B}, 5 \mathrm{~B}, 5 \mathrm{D}, 6 \mathrm{~B}, 6 \mathrm{D}, 7 \mathrm{~A}$, and $7 \mathrm{~B}$ ) and explained about $2.52-6.92 \%$ of the phenotypic variation. For the flag leaf area (FLA), the 40 significant SNP loci identified across six environments were detected on 16 chromosomes $(1 \mathrm{~B}, 2 \mathrm{~A}, 2 \mathrm{~B}, 2 \mathrm{D}, 3 \mathrm{~A}, 3 \mathrm{~B}, 3 \mathrm{D}, 4 \mathrm{~A}, 4 \mathrm{~B}, 4 \mathrm{D}, 5 \mathrm{~B}, 5 \mathrm{D}$, $6 \mathrm{~B}, 6 \mathrm{D}, 7 \mathrm{~A}$, and $7 \mathrm{~B}$ ) and explained about $2.58-6.37 \%$ of the phenotypic variation. For the flag leaf angle (FA), 13 significant SNP loci were detected on nine chromosomes $(1 \mathrm{~B}, 2 \mathrm{~B}, 3 \mathrm{~A}, 3 \mathrm{~B}, 4 \mathrm{~B}, 4 \mathrm{D}, 5 \mathrm{~A}, 6 \mathrm{~A}$, and $6 \mathrm{D})$, accounting for about $2.06-3.35 \%$ of the phenotypic variation. Of the 68 SNPs identified for the flag leaf-associated traits, 11 pleiotropic loci were associated with three traits.

For the maximum tiller number (MTN), 37 significant SNP loci were detected on 14 chromosomes $(1 \mathrm{~A}, 1 \mathrm{~B}, 2 \mathrm{~B}$, $2 \mathrm{D}, 3 \mathrm{~A}, 3 \mathrm{~B}, 4 \mathrm{~B}, 4 \mathrm{D}, 5 \mathrm{~B}, 5 \mathrm{D}, 6 \mathrm{~B}, 6 \mathrm{D}, 7 \mathrm{~A}$, and $7 \mathrm{~B}$ ) and explained about $1.80-5.32 \%$ of the phenotypic variation. Five significant SNP loci for the heading date (HD) were distributed on chromosomes $2 \mathrm{~A}$ and $5 \mathrm{~A}$, accounting for $2.73-5.94 \%$ of the phenotypic variation. Seven significant SNP loci for the mature period (MP) were detected on chromosomes $2 \mathrm{~B}, 3 \mathrm{~B}, 6 \mathrm{~A}$, and $7 \mathrm{~B}$ and accounted for $2.70-3.75 \%$ of the phenotypic variation. The seven 
Table 1 SNP sites detected in two or more traits

\begin{tabular}{|c|c|c|c|c|c|c|}
\hline SNP & Trait & Environment & Chromosome & Position & $-\log _{10} p$ & $\mathrm{R}^{2}(\%)$ \\
\hline RAC875_rep_c111906_144 & FLL/FLA & E2 & $2 \mathrm{~A}$ & $27,967,266$ & $4.45-4.95$ & $2.84-3.23$ \\
\hline Tdurum_contig19022_1524 & FLL/FLA & E2 & $7 B$ & $530,376,060$ & $4.13-4.24$ & $2.61-2.68$ \\
\hline wsnp_CAP11_c2435_1256981 & FLL/FLA/FLW & E2E5 & $7 \mathrm{~A}$ & $655,447,518$ & $5.76-7.74$ & $3.79-5.32$ \\
\hline GENE-0035_150 & FLL/FLA/FLW/MTN & E2E5 & $1 \mathrm{~B}$ & $465,098,532$ & $4.22-6.73$ & $2.65-4.55$ \\
\hline GENE-0993_47 & FLL/FLA/FLW/MTN & E2E5 & $2 B$ & $55,691,934$ & $4.68-7.52$ & $2.99-5.16$ \\
\hline Tdurum_contig73039_241 & FLL/FLA/FLW/MTN & E2E5 & $3 B$ & $527,296,306$ & $5.03-7.47$ & $3.25-5.12$ \\
\hline Tdurum_contig4974_355 & FLL/FLA/FLW/MTN & E2E5 & $4 \mathrm{~B}$ & $95,708,069$ & $4.71-7.29$ & $3.01-4.98$ \\
\hline Ku_c7989_781 & FLL/FLA/FLW/MTN & E2E5 & $5 B$ & $253,378,428$ & $4.28-5.77$ & $2.7-3.82$ \\
\hline D_contig73483_655 & FLL/FLA/FLW/MTN & E2E5 & $5 D$ & $100,546,173$ & $4.7-7.93$ & $3.01-5.47$ \\
\hline GENE-3803_329 & FLL/FLA/FLW/MTN & E2E5 & $6 B$ & $556,487,785$ & $4.14-5.61$ & $2.59-4.37$ \\
\hline BobWhite_c36864_159 & FLL/FLA/FLW/MTN & E2E5 & $7 B$ & $131,745,465$ & $4.19-6.86$ & $2.63-4.85$ \\
\hline Tdurum_contig41918_2469 & FLL/FLA/FLW/MTN & E2E5 & $7 \mathrm{~B}$ & $628,465,395$ & $4.74-7.57$ & $3.03-5.20$ \\
\hline Tdurum_contig42029_1151 & FLL/FLA/FLW/MTN & E2E5 & $7 B$ & $660,237,019$ & $4.78-7.64$ & $3.07-5.25$ \\
\hline BS00099128_51 & FLW/MTN & E2E5 & $2 \mathrm{D}$ & $470,217,019$ & $4.27-4.73$ & $2.91-3.23$ \\
\hline Tdurum_contig17320_458 & FLW/MTN & E2E5 & $3 \mathrm{~A}$ & $170,784,653$ & $4.12-6.46$ & $2.80-4.61$ \\
\hline Excalibur_c43604_751 & FLW/MTN & E2E5 & 3B & $807,286,509$ & $4.16-6.97$ & $2.83-5.02$ \\
\hline Tdurum_contig100205_499 & FLW/MTN & E2E5 & $4 \mathrm{~B}$ & $78,818,313$ & $4.38-6.7$ & $3-4.8$ \\
\hline wsnp_Ex_c402_791233 & FLA/FLW & E2E5 & $1 \mathrm{~B}$ & $548,623,447$ & $5.51-6.37$ & $3.87-4.34$ \\
\hline Excalibur_c89155_115 & FLA/FLW & E5 & $6 B$ & $619,483,986$ & $4.1-4.36$ & $2.78-2.8$ \\
\hline GENE-1343_878 & FLA/FLW/MTN & E2E5 & $2 \mathrm{D}$ & $13,440,948$ & $5.10-6.4$ & $3.47-4.3$ \\
\hline D_F1BEJMU01DOWJ3_176 & FLA/FLW/MTN & E2E5 & $2 \mathrm{D}$ & $138,694,869$ & $5.49-6.38$ & $3.66-4.46$ \\
\hline GENE-0826_51 & FLA/FLW/MTN & E2E5 & $3 \mathrm{~A}$ & $32,151,249$ & $4.94-6.07$ & $3.23-4.09$ \\
\hline Tdurum_contig16643_466 & FLA/FLW/MTN & E2E5 & $3 \mathrm{~A}$ & $549,267,983$ & $4.49-5.85$ & $2.89-4.12$ \\
\hline D_GBF1XID01CVZMX_132 & FLA/FLW/MTN & E2E5 & $5 \mathrm{D}$ & $483,515,041$ & 4.89-6.97 & $3.2-5.02$ \\
\hline IACX1201 & FLA/FLW/MTN & E2E5 & $6 \mathrm{~B}$ & $219,580,396$ & $4.06-5.96$ & $2.65-4.2$ \\
\hline D_contig38762_578 & FLA/FLW/MTN & E2E5 & $6 \mathrm{D}$ & $67,378,176$ & $5.39-6.66$ & $3.75-4.49$ \\
\hline RAC875_c48208_304 & FLA/FLW/MTN & E2E5 & $7 \mathrm{~B}$ & $3,505,857$ & $5.28-6.17$ & $3.49-4.13$ \\
\hline GENE-4534_455 & FLA/FLW/MTN & E2E5 & $7 B$ & $152,051,848$ & $5.33-6.43$ & $3.52-4.32$ \\
\hline Tdurum_contig42179_1562 & PET/MTN & E2E5 & $3 \mathrm{~A}$ & $266,433,409$ & $4.71-7.27$ & $3.19-5.26$ \\
\hline D_contig26931_415 & PET/MTN & E2E5 & $5 \mathrm{D}$ & $283,010,539$ & $4.12-7.34$ & $2.74-5.32$ \\
\hline wsnp_Ex_c14654_22713386 & PET/MTN & E2E5 & $7 \mathrm{~A}$ & $11,098,761$ & $4.53-7.07$ & $3.05-5.1$ \\
\hline BS00044895_51 & PET/MTN & E2E5 & $7 A$ & $211,733,339$ & $4.35-7.05$ & $2.91-5.08$ \\
\hline Tdurum_contig19022_1524 & PET/MTN & E2E5 & $7 \mathrm{~B}$ & $530,376,060$ & $4.6-5.51$ & $3.13-3.85$ \\
\hline Kukri_c56333_138 & MTN/FC & BLUP & $1 \mathrm{~B}$ & $670,176,213$ & $4.50-4.75$ & $1.80-2.77$ \\
\hline BobWhite_c19617_154 & GFR/TGW & BLUP & $2 \mathrm{~B}$ & $209,099,527$ & $4.89-4.91$ & $3.46-3.59$ \\
\hline Kukri_c322_1394 & $\mathrm{FD} / \mathrm{SD}$ & E1/BLUP & $4 \mathrm{~B}$ & $520,238,759$ & $4.64-4.8$ & $3.07-4.07$ \\
\hline Tdurum_contig48366_1324 & $\mathrm{FD} / \mathrm{SD}$ & E1E2/BLUP & $4 \mathrm{~B}$ & $637,387,355$ & $4.13-4.88$ & $2.62-5.02$ \\
\hline Tdurum_contig50783_67 & $\mathrm{FD} / \mathrm{SD}$ & BLUP & $4 \mathrm{~B}$ & $637,387,809$ & $4.07-4.24$ & $2.57-3.11$ \\
\hline RAC875_rep_c105718_585 & FIL/SIL/PH & E3E4E5E6/BLUP & $4 \mathrm{D}$ & $25,989,112$ & $4.09-7.89$ & $2.03-7.56$ \\
\hline BS00044895_51 & FIL/SIL/TH & E1E2 & $7 \mathrm{~A}$ & $211,733,339$ & $4.4-6.47$ & $3.78-5.97$ \\
\hline BS00022854_51 & $\mathrm{SIL} / \mathrm{TH}$ & E1E5 & $5 B$ & $614,983,507$ & $4.29-6.13$ & $2.7-5.62$ \\
\hline Ex_c52589_795 & GPCNGC & E1 & $3 \mathrm{D}$ & $531,375,739$ & $4.36-4.58$ & $2.48-2.53$ \\
\hline
\end{tabular}


significant SNP loci for the grain-filling period (GFP) were detected on chromosomes $2 \mathrm{~A}, 2 \mathrm{~B}, 2 \mathrm{D}$, and $7 \mathrm{~B}$ and accounted for $1.37-2.99 \%$ of the phenotypic variation. Nine significant SNP loci for the grain-filling rate (GFR) were detected on chromosomes 1A, 1B, 2A, 2B, 4A, 4B, and $5 \mathrm{~B}$, accounting for $2.39-3.59 \%$ of the phenotypic variation. Eight significant SNP loci for TGW were detected on chromosomes $1 \mathrm{~B}, 2 \mathrm{~B}, 3 \mathrm{~A}, 3 \mathrm{~B}, 4 \mathrm{~B}$, and $6 \mathrm{D}$, explaining $2.29-3.59 \%$ of the phenotypic variation.

For $\mathrm{PH}, 20$ significant SNP loci were detected on 10 chromosomes $(1 \mathrm{~A}, 1 \mathrm{~B}, 2 \mathrm{~B}, 3 \mathrm{~A}, 3 \mathrm{~B}, 4 \mathrm{~A}, 4 \mathrm{~B}, 4 \mathrm{D}, 5 \mathrm{~A}$, and $6 \mathrm{~B})$ and explained about $1.96-4.42 \%$ of the phenotypic variation. For the diameter of the first internode (FD), 16 significant SNP loci were detected on nine chromosomes $(1 \mathrm{~A}, 1 \mathrm{~B}, 2 \mathrm{~B}, 3 \mathrm{D}, 4 \mathrm{~A}, 4 \mathrm{~B}, 5 \mathrm{~B}, 6 \mathrm{~A}$, and $7 \mathrm{~A})$ and explained about $1.53-4.85 \%$ of the phenotypic variation. Regarding the length of the first internode (FIL), 17 significant SNP loci were detected on eight chromosomes $(1 \mathrm{~A}, 1 \mathrm{~B}, 2 \mathrm{~A}, 3 \mathrm{~A}, 3 \mathrm{~B}, 4 \mathrm{D}, 6 \mathrm{~B}$, and $7 \mathrm{~A})$ and explained about $2.13-5.76 \%$ of the phenotypic variation. For the diameter of the second internode (SD), the 18 significant SNP loci identified across six environments were detected on eight chromosomes $(2 \mathrm{~A}, 2 \mathrm{~B}, 2 \mathrm{D}, 3 \mathrm{~B}, 4 \mathrm{~B}, 5 \mathrm{~B}$, $6 \mathrm{~B}$, and $7 \mathrm{~B}$ ), explaining about $2.15-5.02 \%$ of the phenotypic variation. For the length of the second internode (SIL), 15 significant SNP loci were detected on seven chromosomes $(1 \mathrm{~A}, 1 \mathrm{D}, 4 \mathrm{~B}, 4 \mathrm{D}, 5 \mathrm{~B}, 7 \mathrm{~A}$, and 7D) and explained about $2.57-5.74 \%$ of the phenotypic variation. For $\mathrm{TH}, 45$ significant SNP loci were detected on 15 chromosomes $(1 \mathrm{~B}, 2 \mathrm{~B}, 2 \mathrm{D}, 3 \mathrm{~A}, 3 \mathrm{~B}, 4 \mathrm{~A}, 4 \mathrm{~B}, 4 \mathrm{D}, 5 \mathrm{~B}, 5 \mathrm{D}$, $6 \mathrm{~A}, 6 \mathrm{~B}, 6 \mathrm{D}, 7 \mathrm{~A}$, and $7 \mathrm{~B}$ ), accounting for approximately $2.5-7.13 \%$ of the phenotypic variation. Among them, it is noteworthy that three loci on chromosome $4 \mathrm{~B}$ are associated with FD and SD.

\section{Yield-related traits}

For spike length (SL), nine significant SNP loci were distributed on seven chromosomes $(1 \mathrm{~B}, 3 \mathrm{~A}, 3 \mathrm{D}, 4 \mathrm{~B}, 6 \mathrm{D}$, $7 \mathrm{~A}$, and $7 \mathrm{~B}$ ) and explained about $2.42-4.33 \%$ of the phenotypic variation. Regarding the spikelet number per spike (SNS), 14 significant SNP loci were detected on six chromosomes $(2 \mathrm{~A}, 2 \mathrm{~B}, 2 \mathrm{D}, 4 \mathrm{~B}, 4 \mathrm{D}$, and $7 \mathrm{~A})$, explaining about $1.27-4.02 \%$ of the phenotypic variation. The nine significant SNP loci for KNPS were detected on chromosomes $1 \mathrm{~A}, 3 \mathrm{~A}, 4 \mathrm{~A}, 4 \mathrm{~B}$, and $5 \mathrm{D}$ and accounted for 2.58 $4.32 \%$ of the phenotypic variation. Regarding the percentage of spike-bearing tillers (PET), 11 significant SNP loci were detected on 10 chromosomes $(1 \mathrm{~A}, 2 \mathrm{~A}, 3 \mathrm{~A}, 4 \mathrm{D}$, $5 \mathrm{~B}, 5 \mathrm{D}, 6 \mathrm{~B}, 6 \mathrm{D}, 7 \mathrm{~A}$, and $7 \mathrm{~B}$ ) and explained about 2.74$3.55 \%$ of the phenotypic variation. For the spike number per mu (EPM), 17 significant SNP loci were detected on eight chromosomes (1B, 2A, 4B, 4D, 5A, 5B, 7A, and 7B) and explained about $2.33-8.47 \%$ of the phenotypic variation.

\section{Quality-related traits}

For the grain volume (GV), 17 significant SNP loci were detected on five chromosomes (1B, 3B, 3D, 6A, and 6B) and explained about $2.52-5.01 \%$ of the phenotypic variation. The two significant SNP loci for GPC detected on chromosomes 1A and 3D accounted for $2.35-2.53 \%$ of the phenotypic variation. Two significant SNP loci for WGC were detected on chromosomes $3 \mathrm{D}$ and $5 \mathrm{D}$ and accounted for $2.43-2.90 \%$ of the phenotypic variation. Ten significant SNP loci for the flour content $(\mathrm{FC})$ were detected on chromosomes $1 \mathrm{~B}, 4 \mathrm{~B}, 5 \mathrm{~A}, 5 \mathrm{~B}, 6 \mathrm{~A}$, and $7 \mathrm{~B}$, accounting for $1.80-3.27 \%$ of the phenotypic variation.

\section{Putative candidate gene analysis and expression data}

In our study, the 200-, 380-, and 600-kb sequences flanking the related SNPs in subgenomes A, B, and D, respectively, were identified as potential candidate gene regions. A total of 638 putative candidate genes detected of the significant SNPs flanking-regions based on BLUP data were identified by screening the annotated genes in the recently released genome sequence (IWGSC RefSeq v1.0) (Table S4). We performed subsequent haplotype and expression analysis for the following three critical traits: SNS (Fig. 1), FD (Fig. 2), and GV (Fig. 3).

Regarding the SNPs associated with SNS, an association peak that included four significantly associated SNPs was detected on chromosome 7A (Fig. 1a, b). On the basis of the SNPs on chromosome 7A, three haplotypes were identified, with the mean SNS for haplotype II $(19.57 \pm 1.14)$ significantly lower than the corresponding values for haplotypes I $(19.78 \pm 1.33)$ and III $(20.31 \pm$ 1.43) (Fig. 1c, d). One of the four significant SNPs (BS00026622_51) was located at 942 bp in the third exon of the gene TraesCS7A01G482000. This locus was detected in four environments and in the BLUP model. SNP (C/A) at this location in the relevant genomic regions cause amino acids to change from leucine to isoleucine (Fig. 1e). The expression of the TraesCS7A01G482000 candidate gene when two nodes were detectable was significantly upregulated according to the RNA-seq analysis of the spike (Fig. 1f).

Among the SNPs associated with FD, four similar SNPs were distributed on chromosome $4 \mathrm{~B}$ and all were detected in the BLUP model and in at least one environment (Fig. 2a). These four SNPs were BS00023035_51, Tdurum_contig48366_1324, Tdurum_contig50783_67, and Tdurum_contig50783_285, and four SNPs were separated $470.67 \mathrm{~kb}$ (Fig. 2b). Because of their close genetic relationship and significant correlation, these SNPs were used for the subsequent haplotype analysis, which revealed two distinct haplotypes (I and II). A total of 301 wheat materials were included haplotype I, with an FD of $3.25 \pm 0.48 \mathrm{~cm}$, whereas 208 wheat varieties were included haplotype II, with an FD of $3.17 \pm 0.45 \mathrm{~cm}$ (Fig. 


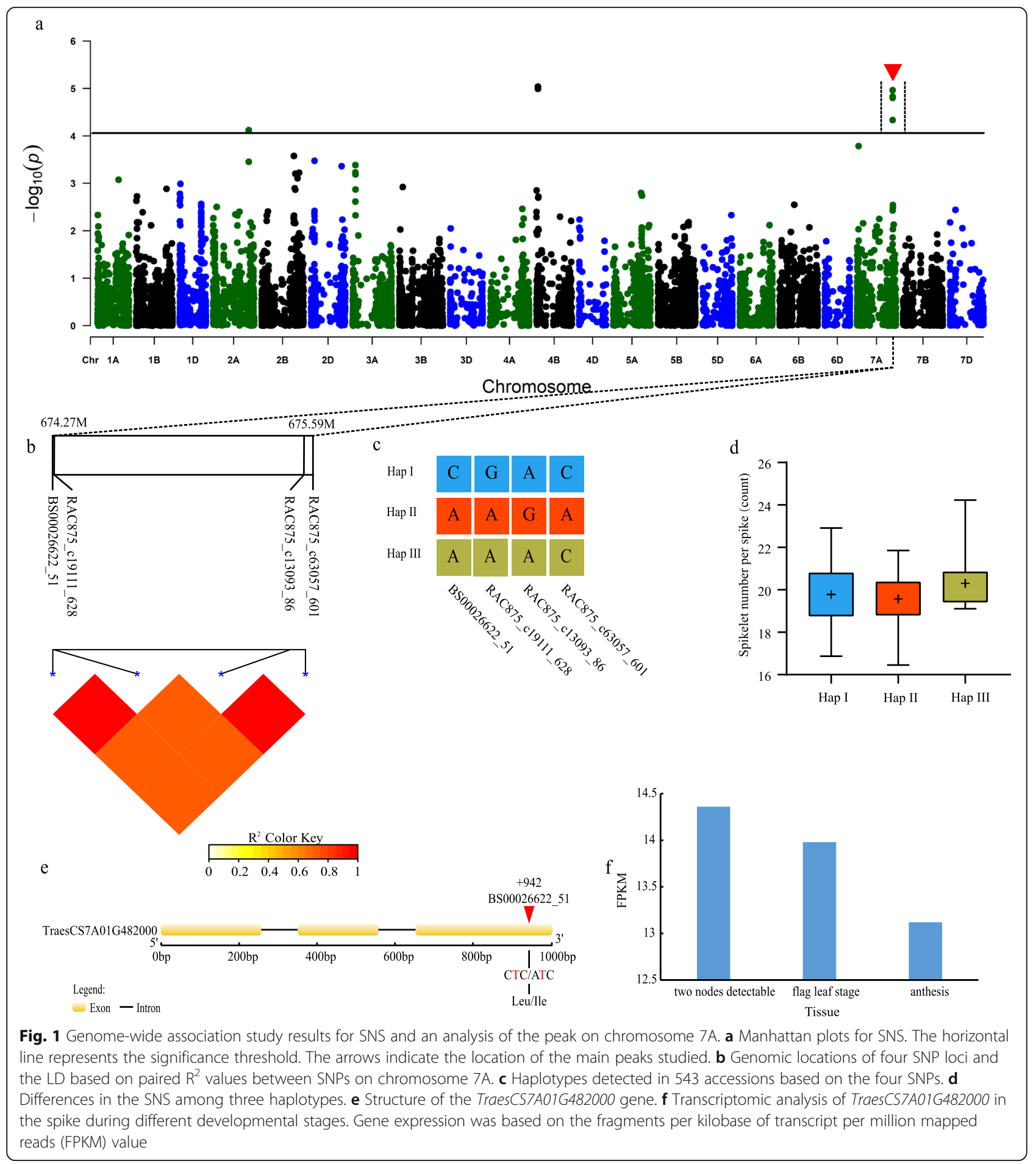

2c, d). The FD of haplotype I was significantly greater than that of haplotype II, implying lodging is less likely for wheat varieties with haplotype I than for varieties with haplotype II. Furthermore, three of the four significant SNPs were detected in the CDS of TraesCS4B01G343700. This gene contains two exons and the CDS comprises $2450 \mathrm{bp}$. The two SNPs located in the second exon resulted in amino acid changes from arginine to histidine and from aspartic acid to asparagine (Fig. 2e). The TraesCS4B01G343700 expression level increased in the stem and internode during wheat growth and development, peaking in the milk stage. This suggests that this gene helps mediate wheat internode growth and development (Fig. 2f). 


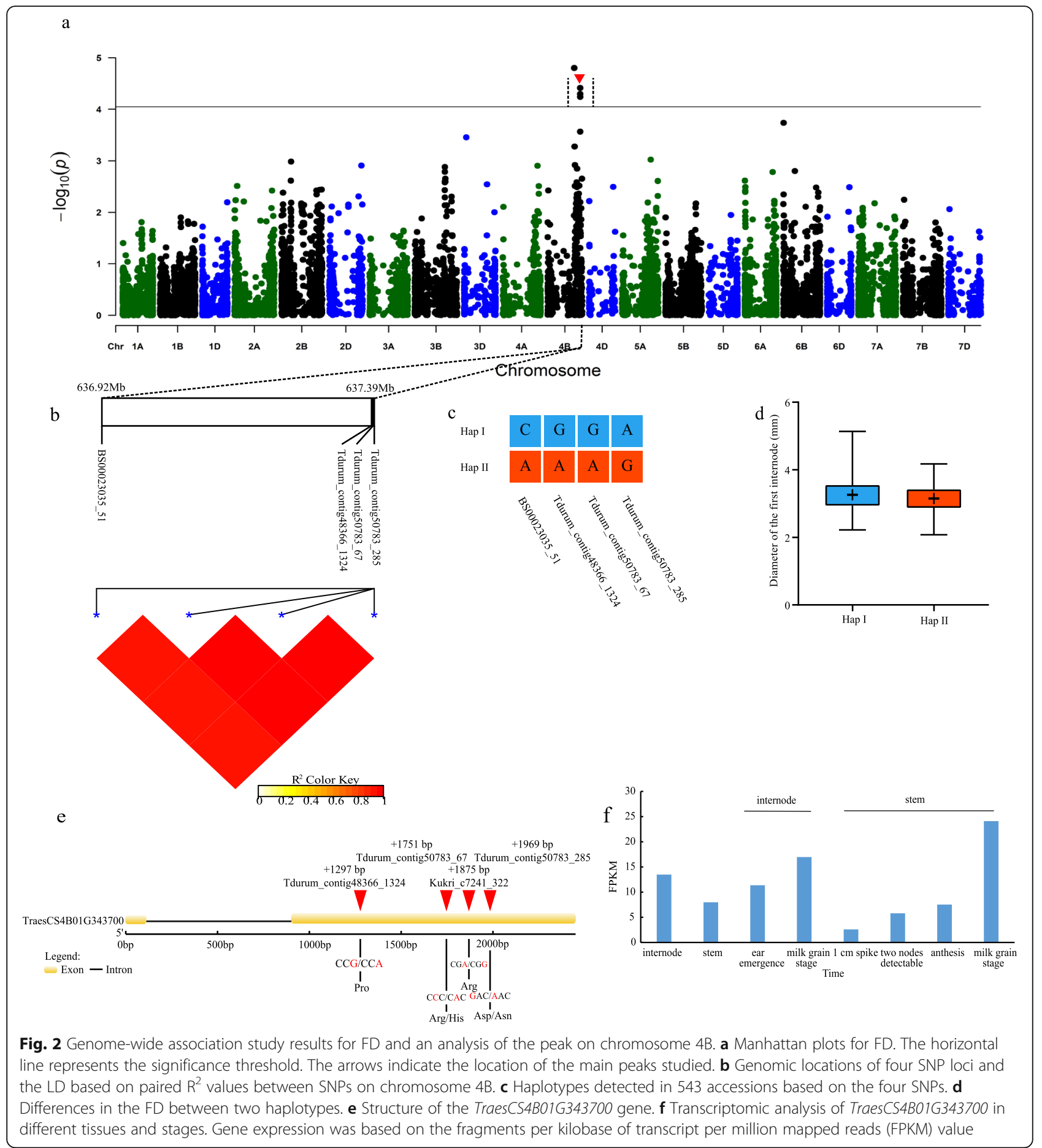

The changes in GV were highly correlated with a set of SNPs in a $1.95 \mathrm{Mb}$ genomic region (528.62$530.57 \mathrm{Mb}$ ) on chromosome 6B (Fig. 3a, b). These loci were detected in multiallelic and BLUP contexts. Three haplotypes were detected in 407 wheat lines on the basis of genotyping results. More specifically, haplotypes I, II, and III were detected in 339, 40, and 28 accessions, respectively. The mean GV of haplotype II $(789.88 \pm 8.58)$ was significantly lower than that of haplotypes I $(798.50 \pm 8.29)$ and III $(799.19 \pm 4.60)$ (Fig. 3c, d). Moreover, one of the four significant SNPs (Excalibur_c11245_880) was detected at $3315 \mathrm{bp}$ in the TraesCS6B01G295400 coding sequence (CDS). The SNP (G/A) leads to changes in amino acids from arginine to histidine (Fig. 3e). The RNA-seq data revealed that this gene 

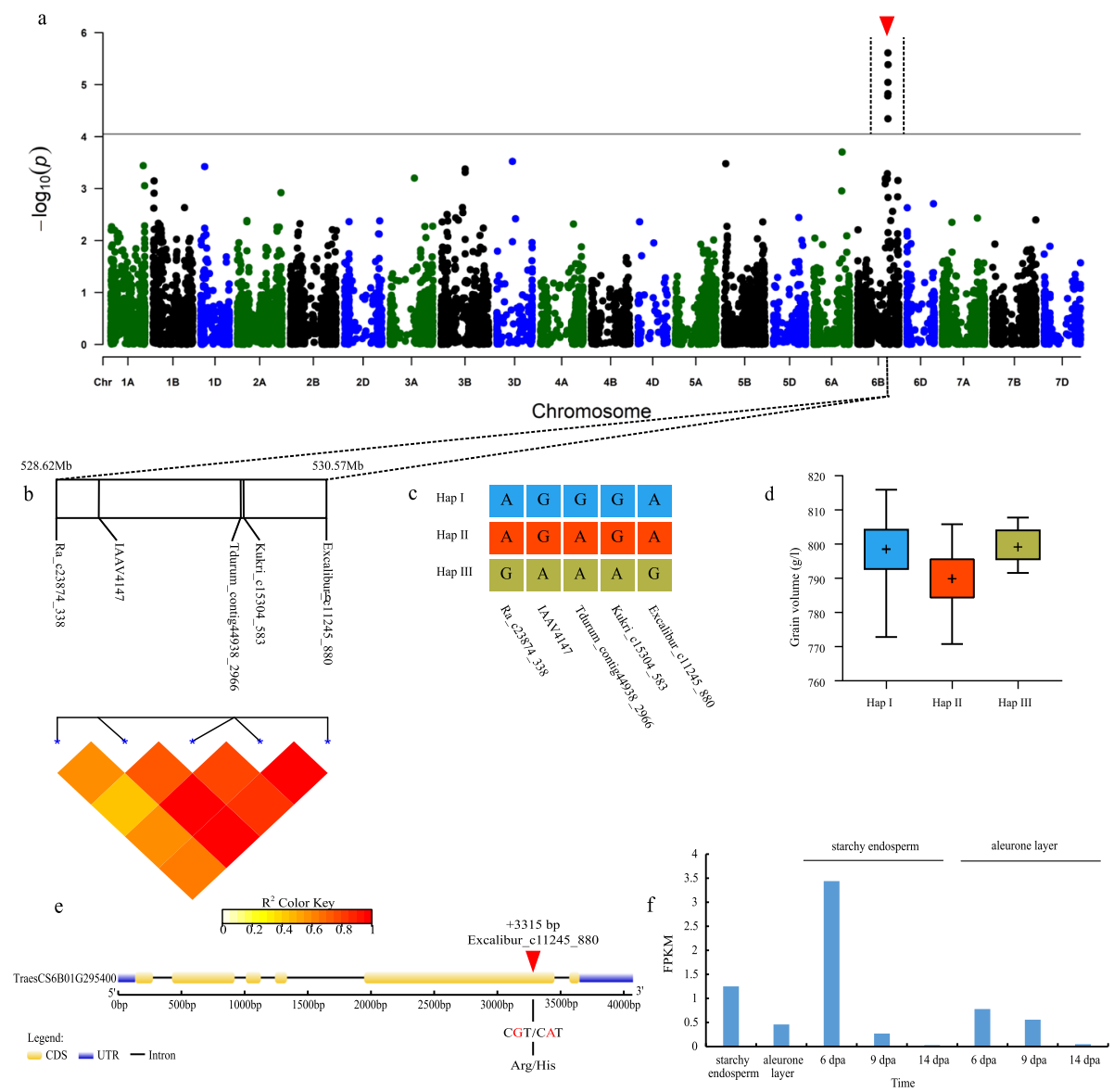

Fig. 3 Genome-wide association study results for GV and an analysis of the peak on chromosome 6B. a Manhattan plots for GV. The horizontal line represents the significance threshold. The arrows indicate the location of the main peaks studied. $\mathbf{b}$ Genomic locations of five SNP loci and the LD based on paired $R^{2}$ values between SNPs on chromosome 6B. $\mathbf{c}$ Haplotypes detected in 543 accessions based on the five SNPS. $\mathbf{d}$ Differences in the GV among three haplotypes. e Structure of the TraesCS6B01G295400 gene. f Transcriptomic analysis of TraesCS6B01G295400 in different tissues and stages. Gene expression was based on the fragments per kilobase of transcript per million mapped reads (FPKM) value

was highly expressed in developing seeds at 6 days post-anthesis (Fig. 3f).

\section{Discussion}

GWAS have been conducted to analyze the yield and quality of various crops, including rice [21], soybean [22], cotton [23], and sorghum [24]. The size of the study population is closely related to the accuracy of the association analysis. Long et al. [25] reported that increasing the population size increases the number of individuals with rare alleles, thereby increasing the accuracy and efficiency of the positioning of rare alleles. Therefore, our GWAS for yield- and quality-related traits involved a wheat $90 \mathrm{~K} \mathrm{SNP}$ array for 543 wheat accessions in multiple environments.

We completed a broad-scale comparison of the results of our study and those of previous investigations. For $\mathrm{PH}$, a locus (RAC875_rep_c105718_585) on chromosome 4D identified in four environments based on BLUP data is about one LD from a QTL (QPH.caas-4DS) described by Li et al. [26], This previously identified QTL was also stably identified in two Chinese bread wheat populations. A QTL (QKNS.caas-4AL) for KNPS between markers Kukri_rep_c106490_583 and RAC875_c29282_566 on chromosome 4A was detected earlier in four environments by Gao et al. [13]. Two sites (Excalibur_c9370_966 and wsnp_Ra_rep_c70233_67968353) related to KNPS revealed in our study are located within this QTL. Gao et al. also reported a stable QTL (QTKW.caas-4BS.1) for TGW between markers BobWhite_c162_145 and Kukri_ c66885_230 on chromosome 4B. In the present investigation, a predicted TGW-associated SNP locus (Tdurum contig97386_207) was detected between two markers on chromosome 4B. Additionally, TaAPO-A1/WAPO-A1 (TraesCS7A02G481600) was identified as a candidate gene for SNS through map-based cloning [27-29]. Two loci 
related to SNS (BS00026622_51 and RAC875_c19111_ 628 ) on chromosome $7 \mathrm{~A}$ identified in four environments based on BLUP data are within one LD of TaAPO-A1. Dobrovolskaya et al. [30] cloned a WFZP (WHEAT FRIZZY PANICLE) gene related to SNS on chromosome 2D. This gene is within one LD of a stable SNS-related locus (GENE-0787_85) revealed in the current study. For the quality-related traits, our GPC locus (GENE-0411_ 807) overlaps the GPC QTL mapped to chromosome 1A by Kumar et al. [31]. Li et al. [32] identified a locus (IWB41869) related to starch granules on chromosome $7 \mathrm{~B}$, which is close to the FC locus (RAC875_c26057_370) we detected on the same chromosome.

In addition, we have also identified new stable SNPs that affect specific genes and have been detected in multiple environments. For example, TraesCS7A01G482000, which is related to SNS, was predicted to encode a haloacid dehalogenase (HAD)-like hydrolase domaincontaining protein. In rice, the overexpression of OsHAD1 reportedly leads to enhanced phosphatase activity and increased total and soluble $\mathrm{P}$ contents in $\mathrm{Pi}$ deficient transgenic seedlings during the early panicle development stage. Increasing the P uptake rate can promote spikelet formation [33, 34]. The RNA-seq data available in an online wheat gene expression database indicated this gene is highly expressed when two nodes are detectable, which coincides with a key period for wheat spikelet development.

Lodging resistance is another important yieldrelated trait. Four significant SNPs for internode diameter were identified on chromosome 4B. These SNPs were detected within TraesCS4B01G343700. In Arabidopsis, AtVPS25 (vacuolar protein sortingassociated protein) regulates auxin biosynthesis via its effects on the expression of specific auxin-related genes. An increase in the auxin content of wheat plants may lead to increased stalk diameters and enhanced lodging resistance [35-37]. A transcriptomelevel analysis of TraesCS4B01G343700 in different tissues and developmental stages proved that this gene is highly expressed during the stem and internode development stage. The expression level peaked in the milk grain stage, implying the changes occurring in this stage have important implications for the lodging resistance of wheat plants.

Regarding the quality-related trait GV, we identified TraesCS6B01G295400, which encodes a LisH domainlike protein, as a candidate gene. In rice, OsLIS-L1 (lissencephaly type-1-like 1 protein) is important for male gametophyte formation, with mutations to this gene resulting in abnormal development. Additionally, the protein encoded by this gene influences grain characteristics and is closely related to the floral development and grain-filling stages [38]. An analysis of publicly available wheat RNA-seq data revealed that this gene is highly expressed in developing seeds, specifically in the starchy endosperm from day 6 to day 14 post-anthesis and showed a gradually decreasing trend. Accordingly, this gene is important for the early grain-filling stage.

\section{Conclusions}

In summary, we conducted a GWAS based on the wheat $90 \mathrm{~K}$ SNP array to investigate the yield- and qualityrelated traits in 543 major wheat accessions. The resulting data were analyzed to identify relevant SNP loci and candidate genes. We are currently developing Kompetitive Allele-Specific PCR markers for the significant loci. These markers will enable researchers and breeders to efficiently transfer alleles into elite wheat genotypes [39]. Additionally, a more thorough characterization of the candidate genes described herein may enhance our understanding of the molecular mechanisms regulating wheat yield and quality.

\section{Methods \\ Plant materials and experimental design}

A bread wheat panel of 543 genotypes including cultivars, regional test lines, and introduced parental lines was used, the details have been published in our previous paper [20]. During the two growing seasons, wheat plants grow in three places in Hebei Province. The locations were Baoding $\left(115.5^{\circ} 48^{\prime} \mathrm{E}, 38^{\circ} 85^{\prime} \mathrm{N}\right)$, Cangzhou $\left(116^{\circ} 80^{\prime} \mathrm{E}, 38^{\circ} 58^{\prime} \mathrm{N}\right)$, and Xingtai $\left(118^{\circ} 9^{\prime} \mathrm{E}, 39^{\circ} 42^{\prime} \mathrm{N}\right)$. The six environments were designated as follows: 2016 Baoding (E1), 2016 Cangzhou (E2), 2016 Xingtai (E3), 2017 Baoding (E4), 2017 Cangzhou (E5), and 2017 Xingtai (E6). The field trial was completed using a completely randomized design. Each plot contained three $1.5 \mathrm{~m}$ rows with $0.25 \mathrm{~m}$ between rows. The plant spacing is about $2.5 \mathrm{~cm}$. Wheat plants were cultivated following normal local practices.

\section{Phenotypic evaluation}

Twenty-five phenotypic traits were measured, including growth and development-related traits (FLL, FLW, FLA, FA, MTN, HD, MP, GFP, GFR, TGW, PH, FD, FIL, SD, SIL, and TH), yield-related traits (SL, SNS, KNPS, PET, and $\mathrm{EPM}$ ), and quality-related traits (GV, GPC, WGC, and FC). The data recorded for each trait are summarized in Table S1. The phenotypic traits were assessed in all six environments. The phenotypic data for each environment and the BLUP data were used for the genome-wide association analysis.

\section{Phenotypic data analysis}

The descriptive statistical analysis and correlation analysis for the phenotypic data were completed using the SPSS 25.0 software. Pearson's correlation coefficients 
were calculated to evaluate the correlations among the traits.

\section{SNP genotyping}

The wheat $90 \mathrm{~K}$ Illumina Infinium SNP array was used to genotype the association panel containing 543 accessions. The SNP data were clustered and automatically called using the Illumina BeadStudio genotyping software (Illumina, San Diego, CA, USA). The data were filtered to remove alleles with a detection rate less than 0.1 and a minor allele frequency less than 0.05 [12]. Additionally, samples with a loss rate greater than $10 \%$ and a heterozygosity frequency greater than $20 \%$ were eliminated.

\section{Genome-wide association analysis}

The population structure, relative kinship, and LD were analyzed in a previous study [20]. In the current study, we completed a GWAS using the GAPIT package [40] in the $\mathrm{R}$ software. A mixed linear model program $(\mathrm{Q}+$ K) [41], with the population stratification results and kinship as covariates, was used to minimize false positives [40]. The $P$ value threshold was calculated based on the number of markers $(P=1 / \mathrm{n}, n=$ total number of SNPs used) as described by Li et al. [42]. Regarding the GWAS results, a $P$ value of $1 / 11,140\left(-\log _{10} P=4.05\right)$ was used as the criterion for identifying significant SNPs.

\section{Prediction of candidate genes and expression analysis}

The 'Chinese Spring' Genome database (IWGSC RefSeq v1.0, http: //www.wheatgenome.org/) was used for predicting candidate genes for the significant sites revealed by the genome-wide association analysis. Specifically, candidate genes around the significant sites were identified according to the differences in the LD decay distance among chromosomal groups. The expression profiles of putative candidate genes were analyzed using a wheat gene expression database available online (http://www.wheat-expression.com/). This database, which includes 850 wheat RNA-sequencing samples and an annotated genome, reveals the similarities and differences between homoeolog expression levels in diverse tissues, developmental stages, and cultivars [33, 43].

\footnotetext{
Abbreviations

EPM: Spike number per mu; FA: Flag leaf angle; FC: Flour content; FD: Diameter of the first internode; FIL: Length of the first internode; FLA: Flag leaf area; FLL: Flag leaf length; FLW: Flag leaf width; GFP: Grainfilling period; GFR: Grain-filling rate; GPC: Grain protein content; GV: Grain volume; HD: Heading date; KNPS: Kernel number per spike; LD: Linkage disequilibrium; MP: Mature period; MTN: Maximum tiller number; PET: Percentage of spike-bearing tillers; PH: Plant height; QTL: Quantitative trait locus; SD: Diameter of the second internode; SIL: Length of the second internode; SL: Spike length; SNS: Spikelet number per spike; TGW: Thousand grain weight; TH: Thrust; WGC: Wet gluten content
}

\section{Supplementary Information}

The online version contains supplementary material available at https://doi. org/10.1186/s12870-021-02925-7.

Additional file 1: Fig. S1 Manhattan plots of GWAS results (BLUP values) excluding SNS, FD and GV traits. The horizontal line represents the significance threshold $\left(-\log _{10} P=4.05\right)$.

Additional file 2: Table S1 Categories and descriptive statistics for the 25 yield- and quality-related traits evaluated in six different environments. Table S2 Correlations among 25 yield- and quality-related traits. Table S3 Basic details regarding the SNP markers used for a genome-wide association study of 543 wheat genotypes. Table S4 Information regarding the candidate genes identified based on BLUP data.

\section{Acknowledgements}

Not applicable.

\section{Authors' contributions}

$Y Z$ and $X J Y$ conceived the project and formulated the scientific objectives; LG, CSM, TFY, KX, HWC and SHZ set up the experimental design and performed the data analysis; $L G$ and $Y Z$ wrote the draft manuscript; and $Y Z$ and $X J Y$ revised the paper. All authors discussed the results and read and approved the final manuscript for publication.

\section{Funding}

This research was supported by the National Key Research and Development Program of China (2017YFD0100600), the National Natural Science Foundation of China (31901539), and the Science and Technology Planning Project of Hebei province (16226320D). These funding bodies had no role in the design of the study and collection, analysis, and interpretation of data and in writing the manuscript.

\section{Availability of data and materials}

All data generated or analyzed during this study are included in this article (and its supplementary information files) or are available from the corresponding author on reasonable request.

\section{Declarations}

Ethics approval and consent to participate

We declare that these experiments comply with the ethical standards and legislations in China, and all wheat varieties were collected in accordance with national guidelines.

\section{Consent for publication \\ Not applicable.}

\section{Competing interests}

The authors declare that they have no competing interests.

Received: 7 November 2020 Accepted: 11 March 2021

Published online: 19 March 2021

\section{References}

1. Shewry PR, Halford NG. Cereal seed storage proteins: structures, properties and role in grain utilization. J Exp Bot. 2002;53(370):947-58. https://doi.org/1 0.1093/jexbot/53.370.947

2. Curtis T, Halford NG. Food security: the challenge of increasing wheat yield and the importance of not compromising food safety. Ann Appl Biol. 2014; 164(3):354-72. https://doi.org/10.1111/aab.12108.

3. Edae EA, Byrne PF, Haley SD, Lopes MS, Reynolds MP. Genome-wide association mapping of yield and yield components of spring wheat under contrasting moisture regimes. Theor Appl Genet. 2014;127(4):791-807. https://doi.org/10.1007/s00122-013-2257-8.

4. Gardiner L, Joynson R, Hall A. Next-Generation Sequencing Enabled Genetics in Hexaploid Wheat. In: Thomas M, Viktor K, editors. Woodhead Publishing. Germany: Academic; 2019. p.49-63.

5. Azadi A, Mardi M, Hervan EM, Mohammadi SA, Moradi F, Tabatabaee MT, Pirseyedi SM, Ebrahimi M, Fayaz F, Kazemi M, Ashkani S, Nakhoda B, Mohammadi-Nejad G. QTL mapping of yield and yield components under 
normal and salt-stress conditions in bread wheat (Triticum aestivum L.). Plant Mol Biol Rep. 2015;33(1):102-20. https://doi.org/10.1007/s11105-014-0726-0.

6. Cui F, Li J, Ding AM, Zhao CH, Wang L, Wang XQ, Li SS, Bao YG, Li XF, Feng DS, Kong LR, Wang HG. Conditional QTL mapping for plant height with respect to the length of the spike and internode in two mapping populations of wheat. Theor Appl Genet. 2011;122(8):1517-36. https://doi. org/10.1007/s00122-011-1551-6.

7. Cui F, Zhao CH, Ding AM, Li J, Wang L, Li XF, Bao YG, Li GM, Wang HG. Construction of an integrative linkage map and QTL mapping of grain yield-related traits using three related wheat RIL populations. Theor Appl Genet. 2014;127(3):659-75. https://doi.org/10.1007/s00122-013-2249-8,

8. Cuthbert JL, Somers DJ, Brlé-Babel AL, Brown PD, Crow GH, Genetics A. Molecular mapping of quantitative trait loci for yield and yield components in spring wheat (Triticum aestivum L.). Theor Appl Genet. 2008;117(4):595608. https://doi.org/10.1007/s00122-008-0804-5.

9. Jia HY, Wan HS, Yang SH, Zhang ZZ, Ma ZQ. Genetic dissection of yieldrelated traits in a recombinant inbred line population created using a key breeding parent in China's wheat breeding. Theor Appl Genet. 2013;126(8): 2123-39. https://doi.org/10.1007/s00122-013-2123-8.

10. Sukumaran S, Dreisigacker S, Lopes M, Chavez P, Reynolds MP. Genomewide association study for grain yield and related traits in an elite spring wheat population grown in temperate irrigated environments. Theor Appl Genet. 2015;128(2):353-63. https://doi.org/10.1007/s00122-014-2435-3.

11. George AW, Cavanagh CJT, Genetics A. Genome-wide association mapping in plants. Theor Appl Genet. 2015;128(6):1163-74. https://doi.org/10.1007/ s00122-015-2497- $x$

12. Li F, Chen BY, Xu K, Wu JF, Song WL, Bancroft I, Harper AL, Trick M, Liu SY, Gao GZ. Genome-wide association study dissects the genetic architecture of seed weight and seed quality in rapeseed (Brassica napus L.). DNA Res. 2014:21:355-67.

13. Gao FM, Wen W, Liu JD, Rasheed A, Yin GH, Xia XC, Wu XX, He ZH. Genome-wide linkage mapping of QTL for yield components, plant height and yield-related physiological traits in the Chinese wheat cross Zhou 8425B/Chinese spring. Front Plant Sci. 2015;6:1099.

14. Chen JH, Zhang FY, Zhao CJ, Lv GG, Sun CW, Pan YB, Guo XY, Chen F. Genome-wide association study of six quality traits reveals the association of the TaRPP13L1 gene with flour colour in Chinese bread wheat. Plant Biotechnol J. 2019;17(11):2106-22. https://doi.org/10.1111/pbi.13126.

15. Liu J, Feng B, Xu ZB, Fan XL, Jiang F, Jin XF, Cao J, Wang F, Liu Q, Yang L, Wang T. A genome-wide association study of wheat yield and qualityrelated traits in Southwest China. Mol Breed. 2017;38:1.

16. Turuspekov Y, Baibulatova A, Yermekbayev K, Tokhetova L, Chudinov V, Sereda G, Ganal M, Griffiths S, Abugalieva S. GWAS for plant growth stages and yield components in spring wheat (Triticum aestivum L.) harvested in three regions of Kazakhstan. BMC Plant Biol. 2017;17:190.

17. Zhuang QS. Chinese wheat improvement and pedigree analysis (in Chinese). Beijing: Agricultural Press; 2003. p. 379-82.

18. Hao CY, Dong YC, Wang LF, You GX, Zhang HN, Ge HM, Jia JZ, Zhang XY. Genetic diversity and construction of core collection in Chinese wheat genetic resources. Chin Sci Bull. 2008:53:1518-26.

19. He ZH, Rajaram S, Xin ZY, Huang GZ. A history of wheat breeding in China. J Comp Neurol. 2001;523:805-13.

20. Zhao Y, Li JH, Zhao RL, Xu K, Xiao YR, Zhang SH, Tian JH, Yang XJ. Genomewide association study reveals the genetic basis of cold tolerance in wheat. Mol Breeding. 2020;40(4):36. https://doi.org/10.1007/s11032-020-01115-x.

21. Yano K, Yamamoto E, Aya K, Takeuchi H, Lo PC, Hu L, Yamasaki M, Yoshida S, Kitano H, Hirano K, Matsuoka M. Genome-wide association study using wholegenome sequencing rapidly identifies new genes influencing agronomic traits in rice. Nat Genet. 2016:48(8):927-34. https://doi.org/10.1038/ng.3596.

22. Fang C, Ma YM, Wu SW, Liu Z, Wang Z, Yang R, Hu GH, Zhou ZK, Yu H, Zhang $M$. Genome-wide association studies dissect the genetic networks underlying agronomical traits in soybean. Genome Biol. 2017;18(1):161. https://doi.org/10.1186/s13059-017-1289-9.

23. Sun ZW, Wang XF, Liu ZW, Gu QS, Zhang Y, Li ZK, Ke HF, Yang J, Wu JH, Wu $L Q$, Zhang GY, Zhang CY, Ma ZY. A genome-wide association study uncovers novel genomic regions and candidate genes of yield-related traits in upland cotton. Theor Appl Genet. 2018;131(11):2413-25. https://doi.org/1 0.1007/s00122-018-3162-y.

24. Boyles RE, Cooper EA, Myers MT, Brenton Z, Rauh BL, Morris GP, Kresovich S. Genome-wide association studies of grain yield components in diverse sorghum germplasm. Plant Genome. 2016;9:17.
25. Long $\mathrm{AD}$, Langley $\mathrm{CH}$. The power of association studies to detect the contribution of candidate genetic loci to variation in complex traits. Genome Res. 1999;9(8):720-31.

26. Li FJ, Wen W, He ZH, Liu JD, Jin H, Cao SH, Geng HW, Yan J, Zhang PZ, Wan YX, Xia XC. Genome-wide linkage mapping of yield-related traits in three Chinese bread wheat populations using high-density SNP markers. Theor Appl Genet. 2018;131 (9):1903-24. https://doi.org/10.1007/s00122-018-3122-6.

27. Kuzay S, Xu YF, Zhang JL, Katz A, Pearce S, Su ZQ, Fraser M, Anderson JA, Brown-Guedira G, DeWitt N, Peters Haugrud A, Faris JD, Akhunov E, Bai GH, Dubcovsky J. Identification of a candidate gene for a QTL for spikelet number per spike on wheat chromosome arm 7AL by high-resolution genetic mapping. Theor Appl Genet. 2019;132(9):2689-705. https://doi.org/1 0.1007/s00122-019-03382-5.

28. Muqaddasi QH, Brassac J, Koppolu R, Plieske J, Ganal MW, Roder MS. TaAPOA1, an ortholog of rice ABERRANT PANICLE ORGANIZATION 1, is associated with total spikelet number per spike in elite European hexaploid winter wheat (Triticum aestivum L.) varieties. Sci Rep. 2019;9:13853.

29. Voss-Fels KP, Keeble-Gagnere G, Hickey LT, Tibbits J, Nagornyy S, Hayden MJ, Pasam RK, Kant S, Friedt W, Snowdon RJ, Appels R, Wittkop B. Highresolution mapping of rachis nodes per rachis, a critical determinant of grain yield components in wheat. Theor Appl Genet. 2019;132(9):2707-19. https://doi.org/10.1007/s00122-019-03383-4.

30. Dobrovolskaya O, Pont C, Sibout R, Martinek P, Badaeva E, Murat F, Chosson A, Watanabe N, Prat E, Gautier N, Gautier V, Poncet C, Orlov YL, Krasnikov AA, Berges H, Salina E, Laikova L, Salse J. FRIZZY PANICLE drives supernumerary spikelets in bread wheat. Plant Physiol. 2015;167(1):189-99. https://doi.org/10.1104/pp.114.250043.

31. Kumar A, Mantovani EE, Simsek S, Jain S, Elias EM, Mergoum M. Genome wide genetic dissection of wheat quality and yield related traits and their relationship with grain shape and size traits in an elite $x$ non-adapted bread wheat cross. PLoS One. 2019;14(9):e0221826. https//doi.org/10.1371/journal.pone.0221826.

32. Li JY, Rasheed A, Guo Q, Dong Y, Liu JD, Xia XC, Zhang Y, He ZH. Genomewide association mapping of starch granule size distribution in common wheat. J Cereal Sci. 2017;77:211-8. https://doi.org/10.1016/j.jcs.2017.08.016.

33. Borrill P, Ramirez-Gonzalez R, Uauy C. expVIP: a customizable RNA-seq data analysis and visualization platform. Plant Physiol. 2016;170(4):2172-86. https://doi.org/10.1104/pp.15.01667.

34. Pandey BK, Mehra P, Verma L, Bhadouria J, Giri J. OsHAD1, a haloacid dehalogenase-like APase, enhances phosphate accumulation. Plant Physiol. 2017;174(4):2316-32. https://doi.org/10.1104/pp.17.00571.

35. Guo MM, Chen M, Liu RB, Ma YZ, Li LC, Xu ZS, Zhang XH, Northwest A. Vacuolar protein sorting AtVPS25 regulates auxin responses in arabidopsis thaliana. Sci Agric Sin. 2014;17:3510-2.

36. Ma QM, Xu YY, Zhao MA, Song XY, Pei YH. Physiological and biochemical indexes related to lodging resistance of maize stalk and expression analysis of key enzyme genes. Plant Physiol J. 2019;8:1123-32.

37. Ren ML, Liu WG, Liu T, Yong-Li DU, Yang WY. Transcriptome analysis of stem morphogenesis under shade stress in soybean. Acta Agron Sin. 2016; 42(9):1319. https://doi.org/10.3724/SP.J.1006.2016.01319.

38. Gao XQ, Chen ZH, Zhang J, Li XW, Chen GX, Li XH, Wu CY. OsLIS-L1 encoding a lissencephaly type-1-like protein with WD40 repeats is required for plant height and male gametophyte formation in rice. Planta. 2012; 235(4):713-27. https://doi.org/10.1007/s00425-011-1532-7.

39. Rasheed A, Wen W, Gao FM, Zhai SN, Jin H, Liu JD, Guo Q, Zhang YG, Dreisigacker S, Xia XC, He ZH. Development and validation of KASP assays for genes underpinning key economic traits in bread wheat. Theor Appl Genet. 2016;129(10):1843-60. https://doi.org/10.1007/s00122-016-2743-x.

40. Lipka AE, Tian F, Wang QS, Peiffer J, Li M, Bradbury PJ, Gore MA, Buckler ES, Zhang ZW. GAPIT: genome association and prediction integrated tool. Bioinformatics. 2012;28(18):2397-9. https://doi.org/10.1093/bioinformatics/ bts444.

41. Yu JM, Pressoir G, Briggs WH, Bi IV, Yamasaki M, Doebley JF, McMullen MD, Gaut BS, Nielsen DM, Holland JB, Kresovich S, Buckler ES. A unified mixed-model method for association mapping that accounts for multiple levels of relatedness. Nat Genet. 2006;38(2):203-8. https://doi. org/10.1038/ng1702.

42. Li H, Peng ZY, Yang XH, Wang WD, Fu JJ, Wang JH, Han YC, Guo TT, Yang $\mathrm{N}$, Liu J, Warburton ML, Cheng YB, Hao XM, Zhang P, Zhao JY, Liu YJ, Wang GY, Li JS, Yan JB. Genome-wide association study dissects the genetic architecture of oil biosynthesis in maize kernels. Nat Genet. 2013;45(1):4350. https://doi.org/10.1038/ng.2484. 
43. Ramírez-González RH, Borrill P, Lang D, Harrington SA, Brinton J, Venturini L, Davey M, Jacobs J, van Ex F, Pasha A. The transcriptional landscape of polyploid wheat. Science. 2018;361(6403):eaar6089.

\section{Publisher's Note}

Springer Nature remains neutral with regard to jurisdictional claims in published maps and institutional affiliations.

Ready to submit your research? Choose BMC and benefit from:

- fast, convenient online submission

- thorough peer review by experienced researchers in your field

- rapid publication on acceptance

- support for research data, including large and complex data types

- gold Open Access which fosters wider collaboration and increased citations

- maximum visibility for your research: over $100 \mathrm{M}$ website views per year

At $\mathrm{BMC}$, research is always in progress. 